\title{
Optimal target localization for subthalamic stimulation in patients with Parkinson disease
}

\section{OPEN}

Marie-Laure Welter, MD $\mathrm{PhD}$

Michael Schüpbach, MD Virginie Czernecki, PhD Carine Karachi, MD, $\mathrm{PhD}$

Sara Fernandez-Vidal, $\mathrm{PhD}$

Jean-Louis Golmard, $\mathrm{MD}, \mathrm{PhD}$

Giulia Serra, MD

Soledad Navarro, MD

Arlette Welaratne

Andréas Hartmann, MD, $\mathrm{PhD}$

Valérie Mesnage, MD

Fanny Pineau

Philippe Cornu, MD, $\mathrm{PhD}$

Bernard Pidoux, MD, $\mathrm{PhD}$

Yulia Worbe, MD, PhD

Panayiotis Zikos, MD

David Grabli, MD, PhD

Damien Galanaud, MD, $\mathrm{PhD}$

Anne-Marie Bonnet, MD Hayat Belaid, MD

Didier Dormont, MD

Marie Vidailhet, MD

Luc Mallet, MD, PhD

Jean-Luc Houeto, MD, $\mathrm{PhD}$

Eric Bardinet, $\mathrm{PhD}$

Jerome Yelnik, MD

Yves Agid, MD, PhD

Correspondence to

Dr. Welter:

marie-laure.welter@psl.aphp.fr

Supplemental data at Neurology.org

\section{ABSTRACT}

Objective: To further determine the causes of variable outcome from deep brain stimulation of the subthalamic nucleus (DBS-STN) in patients with Parkinson disease (PD).

Methods: Data were obtained from our cohort of 309 patients with PD who underwent DBS-STN between 1996 and 2009. We examined the relationship between the 1-year motor, cognitive, and psychiatric outcomes and (1) preoperative PD clinical features, (2) MRI measures, (3) surgical procedure, and (4) locations of therapeutic contacts.

Results: Pre- and postoperative results were obtained in 262 patients with PD. The best motor outcome was obtained when stimulating contacts were located within the STN as compared with the zona incerta (64\% vs 49\% improvement). Eighteen percent of the patients presented a postoperative cognitive decline, which was found to be principally related to the surgical procedure. Other factors predictive of poor cognitive outcome were perioperative confusion and psychosis. Nineteen patients showed a stimulation-induced hypomania, which was related to both the form of the disease (younger age, shorter disease duration, higher levodopa responsiveness) and the ventral contact location. Postoperative depression was more frequent in patients already showing preoperative depressive and/or residual axial motor symptoms.

Conclusion: In this homogeneous cohort of patients with PD, we showed that (1) the STN is the best target to improve motor symptoms, (2) postoperative cognitive deficit is mainly related to the surgery itself, and (3) stimulation-induced hypomania is related to a combination of both the disease characteristics and a more ventral STN location. Neurology ${ }^{\circledR}$ 2014;82:1352-1361

\section{GLOSSARY}

$\mathbf{A D L}=$ activities of daily living; $\mathbf{A S}=$ associative; $\mathbf{D B S}=$ deep brain stimulation; $\mathbf{D S M}-\mathbf{I V}=$ Diagnostic and Statistical Manual of Mental Disorders, 4th edition; MADRS = Montgomery-Åsberg Depression Rating Scale; MDRS = Mattis Dementia Rating Scale; PD = Parkinson disease; $\mathbf{S M}=$ sensorimotor; $\mathbf{S T N}=$ subthalamic nucleus; UPDRS = Unified Parkinson's Disease Rating Scale; $\mathbf{Z I}=$ zona incerta.

Bilateral deep brain stimulation of the subthalamic nucleus (DBS-STN) has been shown to dramatically alleviate motor symptoms in patients with Parkinson disease (PD). ${ }^{1}$ However, some patients show poor relief of parkinsonian motor disability and/or nonmotor side effects, such as a dysexecutive syndrome ${ }^{2}$ or psychiatric symptoms. ${ }^{3}$ These side effects impair the postsurgery quality of life and are responsible for a poor global outcome. ${ }^{4,5}$ Because of these postoperative problems, some authors have (re)proposed other targets such as the globus pallidus interna ${ }^{6,7}$ or the zona incerta $(\mathrm{ZI}){ }^{8}$

From the Université Pierre et Marie Curie-Paris 6 (M.-L.W., M.S., V.C., C.K., S.F.-V., J.-L.G., A.H., V.M., F.P., Y.W., D. Grabli, D. Galanaud, D.D., M.V., L.M., E.B., J.Y., Y.A.), Centre de Recherche de l'Institut du Cerveau et de, la Moelle épinière, UMR-S975, Paris; Inserm (M.-L.W., M.S., V.C., C.K., S.F.-V., A.H., V.M., F.P., Y.W., D. Grabli, D. Galanaud, D.D., M.V., L.M., E.B., J.Y., Y.A.), U975, Paris; CNRS (M.-L.W., M.S., C.K., S.F.-V., A.H., V.M., F.P., Y.W., D. Grabli, D. Galanaud, D.D., M.V., L.M., E.B., J.Y., Y.A.), UMR 7225, Paris; Centre d'Investigation Clinique (M.-L.W., M.S., C.K., G.S., A.H., V.M., F.P., Y.W., P.Z., D. Grabli, A.-M.B., M.V., Y.A.), Département de Neurologie (M.-L.W., V.C., A.W., A.H., V.M., D. Grabli, A.-M.B., M.V., Y.A.), IM2A (V.C., F.P.), Service de Neurochirurgie (C.K., S.N., P.C., H.B.), Department of Clinical Neurophysiology (B.P.), and Service de Neuroradiologie Diagnostique et Fonctionnelle (D. Galanaud, D.D.), Hôpitaux Universitaires Pitié-Salpêtrière/Charles Foix, Assistance Publique-Hôpitaux de Paris, France; Department of Neurology (M.S.), University Hospital, Bern, Switzerland; Centre de Neuroimagerie de Recherche (S.F.-V., D. Galanaud, D.D.), Hôpitaux Universitaires Pitié-Salpêtrière/Charles Foix, Paris, France; Département de Biostatistiques et Information Médicale (J.-L.G.), Hôpitaux Universitaires Pitié-Salpêtrière/Charles Foix, Assistance Publique-Hôpitaux de Paris, ER4 (ex EA3974) Modélisation en Recherche Clinique, Paris, France; Department of Neurology (P.Z.), 251 Hellenic Air Force General Hospital, Athens, Greece; and Department of Neurology (J.-L.H.), CHU Poitiers, France.

This is an open access article distributed under the terms of the Creative Commons Attribution-Noncommercial No Derivative 3.0 License, which permits downloading and sharing the work provided it is properly cited. The work cannot be changed in any way or used commercially. Go to Neurology.org for full disclosures. Funding information and disclosures deemed relevant by the authors, if any, are provided at the end of the article. 
Several preoperative clinical factors are predictive of some of the postoperative difficulties with DBS-STN: (1) older age, (2) parkinsonism with poor response to dopaminergic treatment, ${ }^{9}$ (3) preoperative cognitive deficit such as executive dysfunction, ${ }^{2}$ or (4) focal brain atrophy. ${ }^{10}$ Ventral location of the STN stimulating contact may provoke transient postsurgical hypomania. ${ }^{11,12}$ The role of preoperative factors, ${ }^{13}$ surgical procedure, ${ }^{14,15}$ locations of stimulating contacts, ${ }^{16,17}$ and postoperative management ${ }^{18}$ on the postoperative motor benefit and side effects has already been independently studied in small cohorts of patients.

Our goal was to delve further in this analysis by closely examining our large and homogeneous single-center cohort of 309 patients with PD who underwent surgery within a 13-year period, evaluating patients before, during, and 1 year after DBS-STN. Specifically, we wished to determine the ideal target within the STN area that showed the greatest improvement and fewest side effects for patients with PD. We were also interested in which clinical and surgical factors might be relevant for the postoperative outcome with DBS-STN. We assessed the link between the specific motor, cognitive, and psychiatric outcomes after surgery and the preoperative PD clinical features, MRI measures, surgical procedure, and locations of stimulating contacts that might help us to define the best target for a given patient.

METHODS Patients. Between February 1996 and July 2009 309 patients with PD underwent DBS-STN at the PitiéSalpêtrière Hospital (Paris, France). Patients were deemed suitable for surgery according to the following criteria': (1) age younger than 70 years (mean age: $54.8 \pm 8.8$ years, except in 9 patients); (2) a severe form of the disease (Hoehn and Yahr stage $\geq 2.5$ ); (3) $>40 \%$ decrease in motor symptoms with levodopa treatment; and (4) presence of disabling levodopa-induced motor complications despite optimal medical treatment. Exclusion criteria included dementia, ongoing psychiatric disturbances, surgical contraindications, and relevant brain lesions detected on MRI.

Standard protocol approvals, registrations, and patient consents. This study received approval from the local ethics committee, and all patients gave written informed consent to participate in this study.

Neurosurgical procedure. Quadripolar electrodes (model 3389-28; Medtronic, Minneapolis, MN) were bilaterally implanted, combining intraoperative microelectrode recordings and stimulation, and connected to a subcutaneous pulse generator (Medtronic). Stimulation measures (pulse width, frequency, intensity) were adjusted using an external programmer. ${ }^{19}$

Clinical evaluation. Evaluation of patients was performed 3 months before and 1 year after surgery. ${ }^{9}$

Parkinsonian motor disability. The activities of daily living (ADL) score (Unified Parkinson's Disease Rating Scale [UPDRS] part II) was assessed by patient interview in the "off" and "on" drug conditions.

Before surgery, the motor disability score (UPDRS part III) was examined in the off condition, after a 12-hour interruption of antiparkinsonian medication, and best on-drug condition ("residual" score), after the administration of a single suprathreshold dose of levodopa. Four subscores were calculated: (1) tremor, (2) rigidity, (3) akinesia, and (4) axial. After surgery, these scores were evaluated in 4 conditions, the same day and in the same order: (1) on stimulation (with chronic stimulation measures) and off drug; (2) off stimulation and off drug, after stimulation stopped for at least 90 minutes; (3) off stimulation and on drug, after the administration of the suprathreshold dose of levodopa; and (4) on stimulation and on drug.

Cognitive status. Neuropsychological evaluation focused on executive functions, attention, memory, and visuoconstructive abilities, ${ }^{20}$ by using (1) the Mattis Dementia Rating Scale (MDRS) (range: 0-144), with low scores indicating worse cognitive performance ${ }^{21}$; (2) the "frontal score," determined on a 50-point scale, including the Modified Wisconsin Card Sorting Test (scale 0-20) and verbal fluency ${ }^{20}$; and (3) the Free and Cued Selective Reminding Test to assess memory. ${ }^{20}$

Psychiatric status. Depressive symptoms were assessed with the Montgomery-Åsberg Depression Rating Scale (MADRS) (range: 0-60; depression diagnosis: score $>13$ ). ${ }^{22}$ Hypomania and major depressive disorder were examined using a behavioral evaluation including both a semistructured psychiatric interview based on DSM-IV criteria (Mini-International Neuropsychiatric Inventory) and a nonstandardized psychiatric interview. ${ }^{23}$

Antiparkinsonian treatment and stimulation parameter settings. The levodopa-equivalent dosage and stimulation measures were also noted. Levodopa-related complications were evaluated using the UPDRS part IV.?

MRI acquisition and analysis. MRI acquisition was performed the day before surgery, with the stereotactic Leksell frame in place, and an MRI or 3-dimensional helical tomodensitometry was performed the following day to visualize electrode tracks and determine contact locations. ${ }^{19}$ A voxel-based morphometric analysis was performed on the preoperative T1 images (with no gadolinium) to quantify changes in the gray and white matter concentration ( $\mathrm{n}=160$ patients).

The location of electrodes was obtained using a deformable 3-dimensional histologic atlas of the basal ganglia. ${ }^{24,25}$ Within the STN, 3 functional territories were defined, i.e., posteriorsensorimotor $(\mathrm{SM})$, intermediate-associative $(\mathrm{AS})$, and anteriorlimbic parts, by analogy with tract tracing data obtained in monkeys. ${ }^{26}$ The contact coordinates in the normalized atlas space with reference to the anterior commissure-posterior commissure system were measured relative to the posterior commissure point (absolute laterality: X; anteroposteriority: Y; depth: Z). ${ }^{25}$

Statistical analysis. Changes in scores between baseline and the 1-year follow-up were determined with respect to the same preoperative drug condition. The relationship between the stimulating contact coordinates and the postoperative changes was assessed using a univariate $z$ correlation test. The mean coordinates of the stimulating contacts were chosen as cutoff points to further determine the effects of contact coordinates 


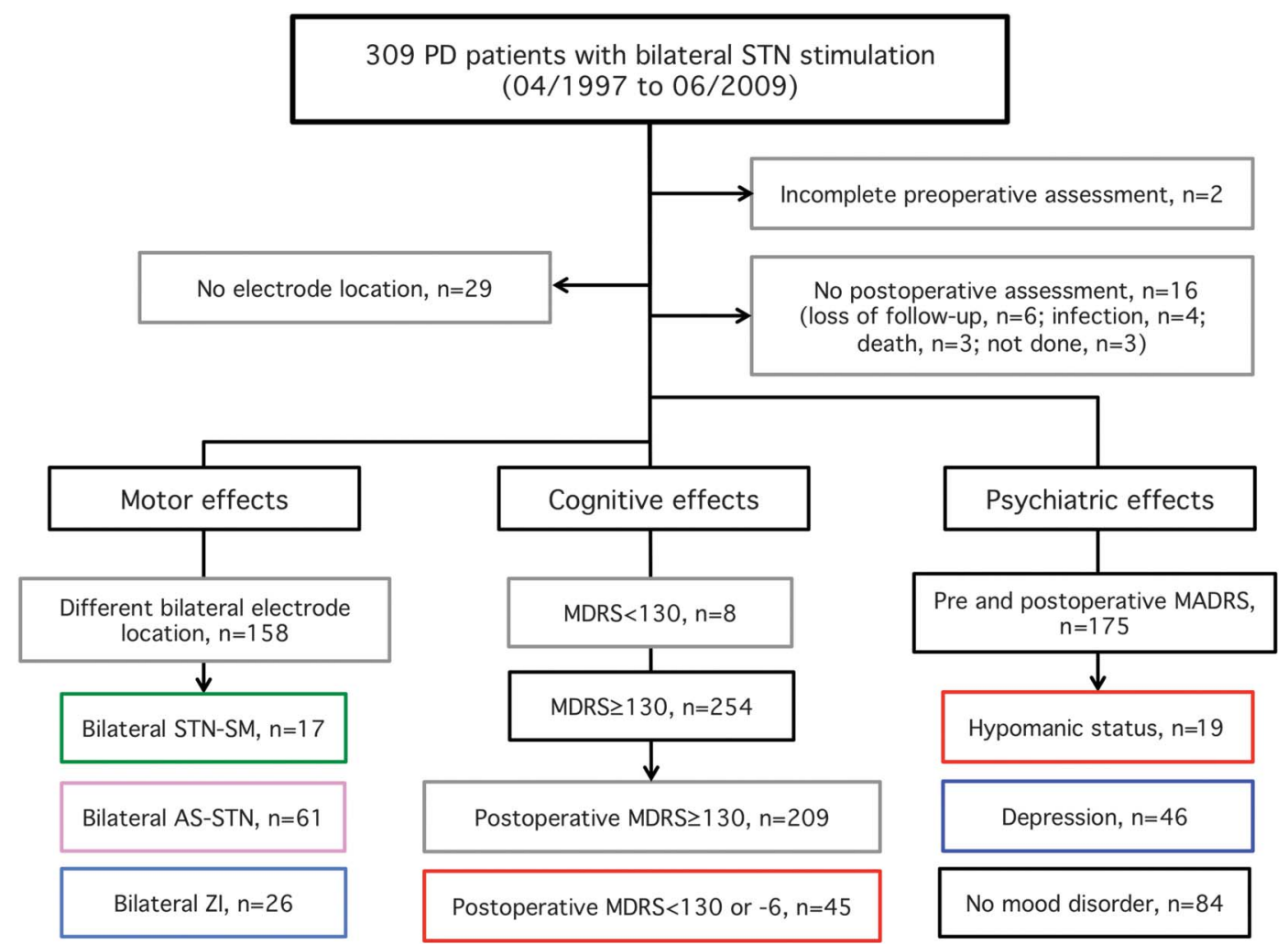

AS = associative; MADRS = Montgomery-Åsberg Depression Rating Scale; MDRS = Mattis Dementia Rating Scale; PD = Parkinson disease; SM = sensorimotor; STN = subthalamic nucleus; $\mathrm{ZI}=$ zona incerta.

on the postoperative clinical outcome by using Student $t$ tests. Statistical analyses were performed using the SAS statistical software package, version 9.2 (SAS Institute Inc., Cary, NC). The level of significance was set at $p<0.01$.

Motor outcome. The role of contact location in the postoperative outcome between patients with bilateral stimulation of the SM-STN, the AS-STN, or the ZI (figures 1 and 2A) was tested using the nonparametric Kruskal-Wallis tests.

Cognitive outcome. Patients with a preoperative MDRS score $<130$ were excluded from this part of the study (figure 1). Postoperative cognitive decline was defined as a decrease more than mean $+1 \mathrm{SD}$ in the MDRS after surgery and/or MDRS score $<130$. To determine which factors differed between patients with vs without postoperative cognitive decline, we performed Student $t$ tests for continuous variables and Fisher exact tests for categorical variables.

Psychiatric outcome. Change in the MADRS score after surgery was the main outcome variable. To determine which factors differed between patients with vs without postoperative depression (MADRS score $>13$ ), we performed Student $t$ tests for continuous variables and Fisher exact tests for categorical variables. Pre- and postoperative data obtained in patients with postoperative depression, transient hypomanic status, or no mood disorders were compared using nonparametric Kruskal-Wallis tests. See e-Methods on the Neurology ${ }^{\circledR}$ Web site at Neurology.org for further details of the methods.

RESULTS Among the 309 patients with PD who underwent bilateral STN stimulation between January 1996 and July 2009, 47 were excluded from the final statistical analysis (figure 1). After these exclusions, we were able to assess the effects of bilateral stimulation on motor, cognitive, and psychiatric symptoms and the therapeutic contact location from a total of 262 patients with PD (103 women/159 men; mean age: $57.6 \pm 8.1$ years; mean disease duration: $12.8 \pm 5.1$ years) (figure 1 , table 1 ).

Contact locations. The distribution of the stimulating contact locations is shown in figure 2. Our method led to the right and left stimulating contacts being bilaterally located in the posterior-SM-STN in 17 patients, the intermediate-AS-STN in 61 patients, and the ZI in 26 patients (figure 1 and figure 2, $\mathrm{A}$ and B). In 158 patients, the 2 stimulating contacts were not bilaterally located in the same subterritory of the STN (figure 1 and figure 2, A and B).

Motor outcome. Patients with PD with SM- or AS-STN stimulation showed lower residual parkinsonian motor disability and akinesia scores (on stimulation, off treatment) in comparison to patients with ZI stimulation (figure 2C), with no significant difference in preoperative features among the 3 groups (table e-1). None of the tremor, rigidity, and axial subscores (table e-1, figure 2C), antiparkinsonian drug treatment (table e-1), or parameter settings (not shown) showed significant differences. 

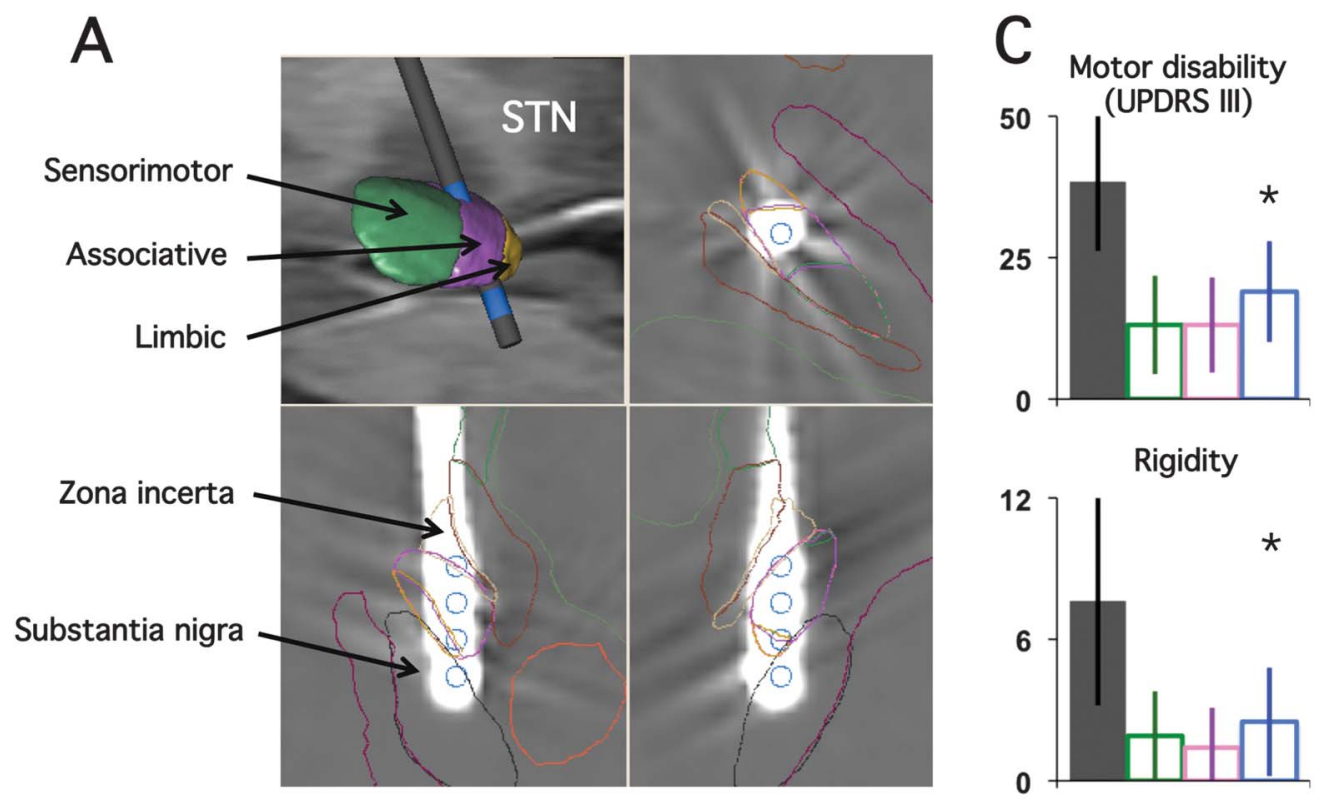

B
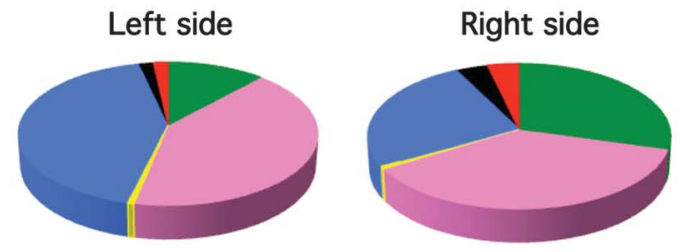
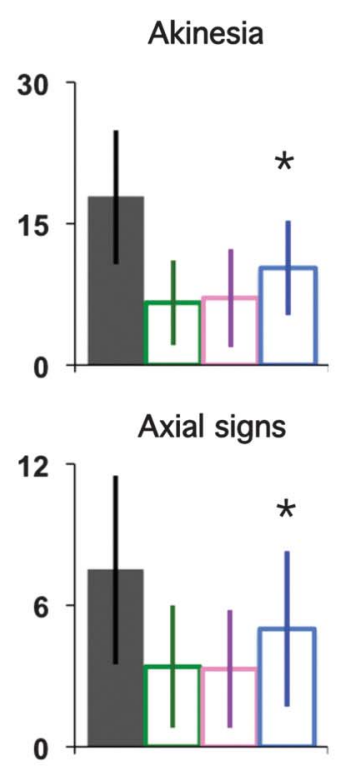
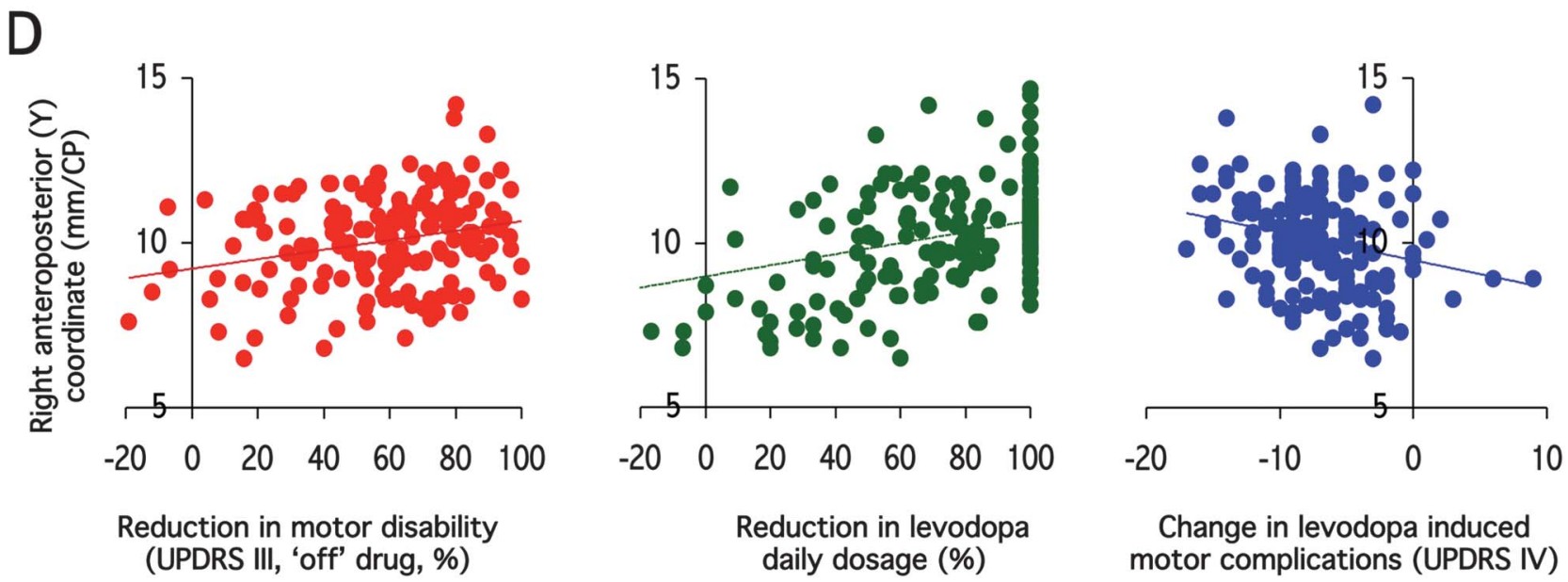

Change in levodopa induced motor complications (UPDRS IV)

(A) Example of one electrode location reconstructed on the 3-dimensional digitized basal ganglia atlas showing the 4 stimulating contacts (blue cylinder, upper left image). The position of each contact is seen on the axial (upper right), sagittal (lower left), and coronal (lower right) images reconstructed in the electrode plane. The location of the stimulating contact in the sensorimotor (SM, green), associative (AS, pink), or limbic (LI, yellow) parts of the subthalamic nucleus (STN), or outside the STN, such as in the substantia nigra (SN, black, located ventrally to the STN), the zona incerta/Forel field area (ZI, yellow, located medially to the STN), or the internal capsule (IC, red, located laterally to the STN), can therefore be accurately determined. (B) Relative distribution of locations of the chronically implanted stimulating contacts in the 262 patients with Parkinson disease, in the left and right hemispheres. (C) Effects of the bilateral stimulation of the SM-STN (green columns) vs AS-STN (pink columns) vs ZI (blue columns) on parkinsonian motor disability (Unified Parkinson's Disease Rating Scale [UPDRS] part III), rigidity, akinesia, and axial signs 1 year after surgery (on stimulation, off drug). The first gray column represents the scores before surgery without antiparkinsonian treatment (off drug). Asterisks indicate significant differences between groups. (D) Relationship between the anteroposterior $(\mathrm{Y})$ coordinate of the right stimulating contact and the improvement in motor disability with bilateral stimulation alone (on stimulation, off drug; left graph), reduction in the levodopa replacement therapy (middle graph), and change in levodopa-induced motor complications (right graph), 12 months after surgery. CP = commissure posterior.

The decrease in parkinsonian motor disability and axial scores and levodopa daily dose under bilateral DBS-STN was significantly related to the right anterior-Y coordinate of the stimulating contact $(p<0.01$, figure 2D). The change in levodopainduced motor complications (UPDRS IV) was also significantly related to both the right and left anterior$\mathrm{Y}$ coordinates of the contacts ( $p<0.01$, figure $2 \mathrm{D})$. 
Table 1 UPDRS scores, cognition, depression, and dopaminergic drug treatment

\begin{tabular}{|c|c|c|c|c|}
\hline & Baseline & $12 \mathrm{mo}$ & $\begin{array}{l}\text { Change between } \\
\text { baseline and } 12 \text { mo }\end{array}$ & $p$ \\
\hline \multicolumn{5}{|l|}{ UPDRS } \\
\hline \multicolumn{5}{|l|}{ Part II: ADL } \\
\hline Off treatment & $21.6(7.8)$ & $11.4(6.4)$ & $-10.3(-11.4$ to -9.2$)$ & $<10^{-4 a}$ \\
\hline On treatment & $6.6(5.4)$ & $8.2(5.6)$ & $1.6(0.8-2.4)$ & $0.0001^{\circ}$ \\
\hline \multicolumn{5}{|l|}{ Part III: motor } \\
\hline Off treatment & 38.7 (14.3) & $14.8(9.5)$ & $-23.9(-25.8$ to -22.2$)$ & $<10^{-4 a}$ \\
\hline On treatment & $9.3(7.2)$ & $7.5(6.0)$ & $-1.7(-1.0$ to -2.4$)$ & $<10^{-4 a}$ \\
\hline \multicolumn{5}{|l|}{ Part III: akinesia } \\
\hline Off treatment & $18.3(6.8)$ & $8.1(5.6)$ & $-10.3(-11.2$ to -9.4$)$ & $<10^{-4 a}$ \\
\hline On treatment & $4.9(4.1)$ & 4.1 (3.8) & $-0.6(-1.1$ to -0.1$)$ & 0.023 \\
\hline \multicolumn{5}{|l|}{ Part III: rigidity } \\
\hline Off treatment & $7.8(4.1)$ & $2.1(2.4)$ & $-5.7(-6.2$ to -5.2$)$ & $<10^{-4 a}$ \\
\hline On treatment & $1.7(2.5)$ & $1.0(1.5)$ & $-0.7(-1.0$ to -0.4$)$ & $<10^{-4 a}$ \\
\hline \multicolumn{5}{|l|}{ Part III: tremor } \\
\hline Off treatment & $5.0(5.1)$ & $1.3(2.2)$ & $-3.7(-4.3$ to -3.1$)$ & $<10^{-4 a}$ \\
\hline On treatment & $0.5(1.2)$ & $0.3(0.8)$ & $-0.2(-0.4$ to 0.0$)$ & $0.002^{\mathrm{a}}$ \\
\hline \multicolumn{5}{|l|}{ Part III: axial signs } \\
\hline Off treatment & $7.5(4.1)$ & $3.4(2.8)$ & $-4.2(-4.7$ to -3.7$)$ & $<10^{-4 a}$ \\
\hline On treatment & $2.2(2.2)$ & $2.2(2.1)$ & -0.1 ( -0.4 to 0.2$)$ & 0.70 \\
\hline Part IV: levodopa-related complications & $9.3(3.5)$ & $2.4(2.4)$ & $-6.8(-7.3$ to -6.3$)$ & $<10^{-4 a}$ \\
\hline \multicolumn{5}{|l|}{ Antiparkinsonian drug treatment } \\
\hline Levodopa dosages, mg/d & 889 (373) & $243(278)$ & $-648(-696$ to -600$)$ & $<10^{-4 a}$ \\
\hline Dopamine agonist dosage, $\mathrm{mg} / \mathrm{d}$ & $320(286)$ & $128(190)$ & $-191(-227$ to -155$)$ & $<10^{-4 a}$ \\
\hline \multicolumn{5}{|l|}{ Cognition-depression } \\
\hline Global cognition, MDRS & $138.5(5.1)$ & $137.2(7.7)$ & $-1.2(-2.0$ to -0.4$)$ & $0.002^{\mathrm{a}}$ \\
\hline mWCST & $16.5(4.4)$ & $16.6(4.5)$ & $0.0(-0.5$ to 0.5$)$ & 0.85 \\
\hline Frontal score & $43.1(7.0)$ & $42.4(7.1)$ & -0.5 (-1.3 to 0.3$)$ & 0.15 \\
\hline Depression, MADRS & $8.2(5.5)$ & $8.2(7.0)$ & $-0.5(-1.7$ to 0.7$)$ & 0.46 \\
\hline
\end{tabular}

Abbreviations: $A D L=$ activities of daily living; MADRS = Montgomery-Åsberg Depression Rating Scale; MDRS = Mattis Dementia Rating Scale; mWCST = modified Wisconsin Card Sorting Test; UPDRS = Unified Parkinson's Disease Rating Scale.

Data are mean (SD). UPDRS score ranges: ADL 0-52, motor 0-108, akinesia 0-40, rigidity 0-20, tremor 0-28, axial signs 0-20, and levodopa-related complications 0-44 (high scores = worse clinical assessment of the patient's Parkinson disease). Cognition score ranges: MDRS 0-144, mWCST 0-20, and frontal score 0-50 (high scores = better cognitive function). Depression: MADRS 0-60 (high score = worse depressive signs).

a Significant differences.

Patients with PD who had higher $\mathrm{Y}$ coordinates $(>10.6 \mathrm{~mm}$, right side) vs lower $(\leq 10.6 \mathrm{~mm})$ showed significantly greater improvements in motor disability and decreases in levodopa-induced motor complications and levodopa daily dose $(p<0.01)$ (figure e-1).

Cognitive outcome. The MDRS score was significantly lower after surgery (table 1), with $18 \%$ of patients showing a decrease of $>6$ points $(n=31)$ and/or an MDRS score $<130$ ( $\mathrm{n}=14$ ) (figure 1$)$. Patients with postoperative cognitive decline showed greater decreases for all of the cognitive domains explored (except the visuoconstructive test) and higher scores for ADL, motor disability, and akinesia scores (figure $3 \mathrm{~A}$, table e-2). Preoperative clinical features and brain MRI white and gray matter densities (voxel-based morphometry) showed no significant differences between the 2 groups (table e-2). Perioperative confusion and psychosis were more frequent in patients who went on to develop a cognitive decline (24\% vs $6 \%, p<0.001$ ) (table e-3).

The stimulating contacts were located differently in the 2 groups, with a more frequent position within 
Figure 3 Postoperative parkinsonian disability and stimulating contact location in PD patients with vs without cognitive decline 1 year after surgery

\section{A}

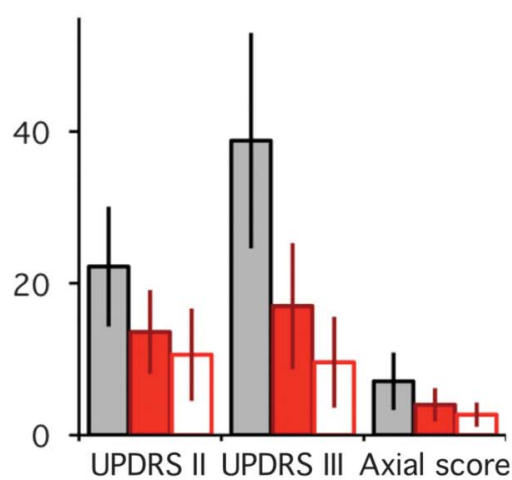

Cognitive stability

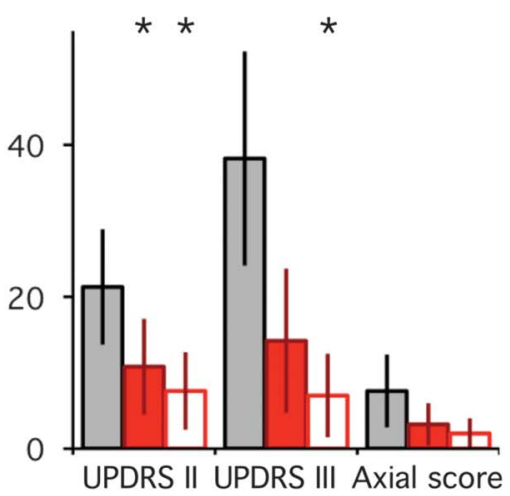

C

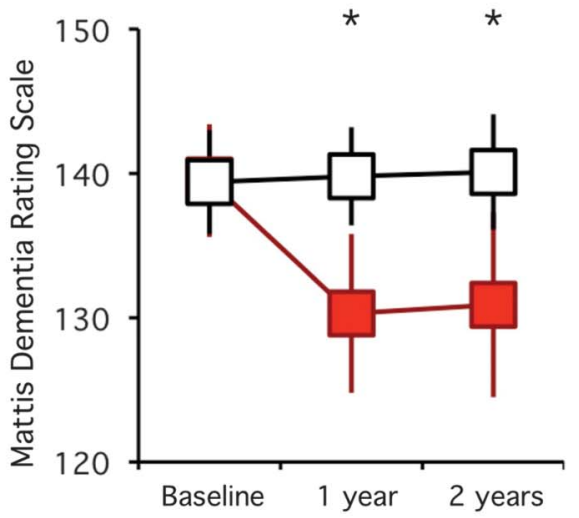

Before surgery OFF treatment

After surgery ON stimulation: $\square$ OFF treatment $\square$ ON treatment

B Cognitive decline

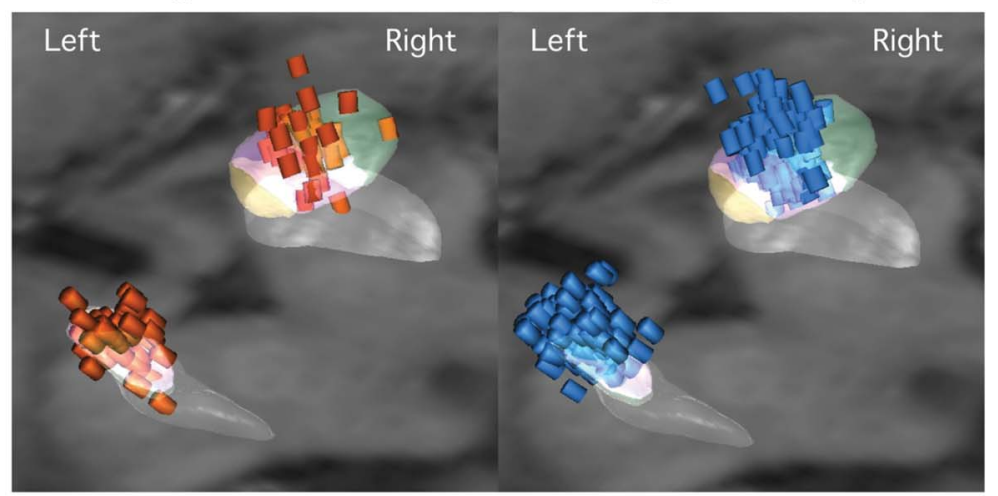

$D$

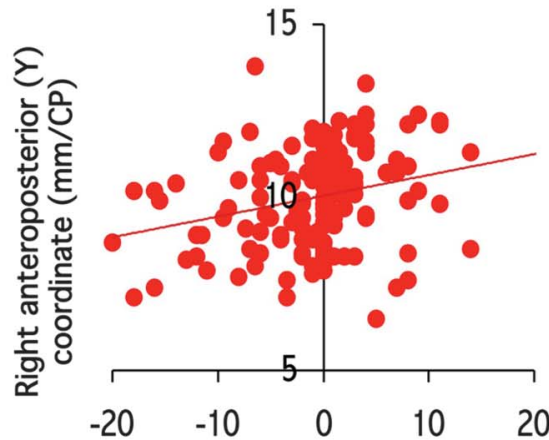

Change in the 'frontal' score

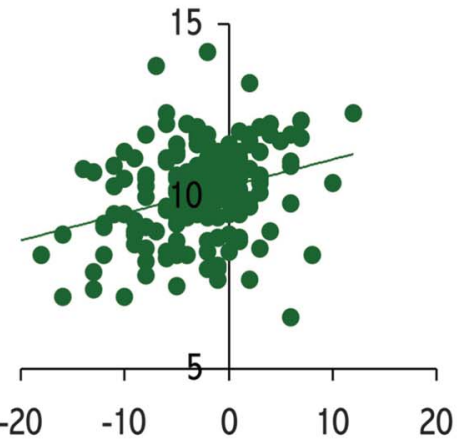

Change in the category verbal fluency score
Right side
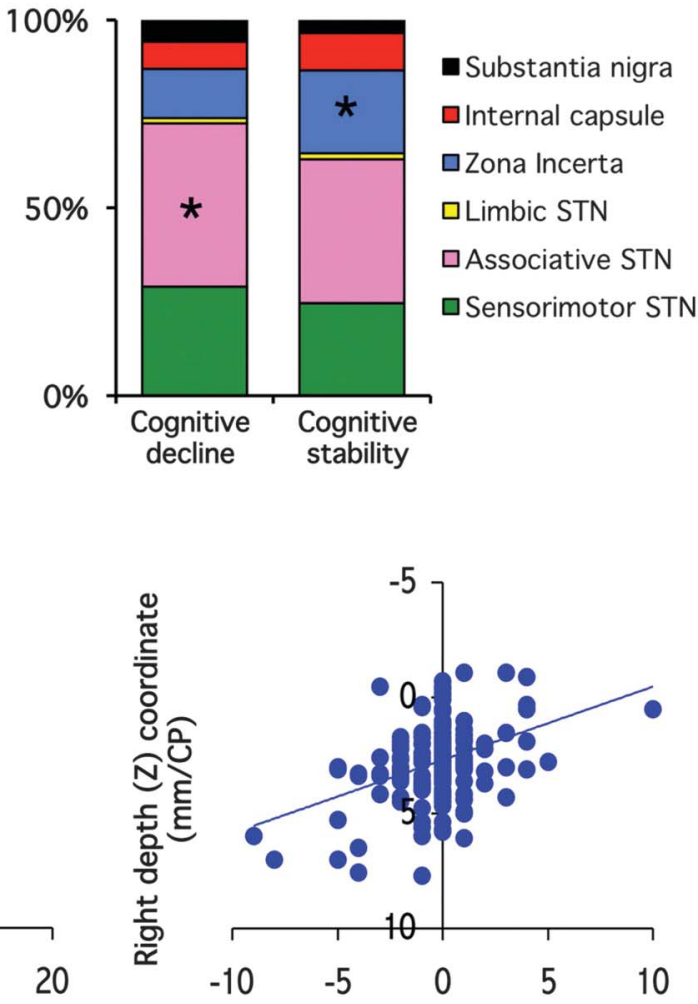

Change in the memory-MDRS score

(A) Differences in parkinsonian activities of daily living (UPDRS part II), motor disability (UPDRS part III), and axial motor sign scores with bilateral subthalamic stimulation alone (OFF, solid red bars) or with drug (ON, empty red bars) in patients with PD who had postoperative cognitive decline (left panel) vs cognitive stability (right panel). The first bars (gray) represent the results obtained for the same scores in the off-drug condition before surgery in each group. (B) Location of the stimulating contacts of the patients with PD who had postoperative cognitive decline (left panel, red cylinders) vs cognitive stability (right panel, blue cylinders). The graph represents the relative proportion of stimulating contacts located within the different subthalamic subregions (sensorimotor, associative, and limbic) and surrounding areas (zona incerta/Forel field, internal capsule, substantia nigra pars reticulata). (C) Changes in the mean MDRS score in PD patients with (filled red squares) vs without (black squares) cognitive decline, 1 and 2 years after surgery. Note that in both groups cognitive status did not significantly change between the first and the second year postsurgery. (D) Relationship between the anteroposterior $(\mathrm{Y})$ coordinate of the right stimulating contact and the change in the frontal score (left panel) and category verbal fluency (middle panel), and the depth (Z) of the right stimulating contact and the change in the MDRS score (right panel). Asterisks indicate significant differences between the 2 groups. $\mathrm{CP}=$ commissure posterior; MDRS = Mattis Dementia Rating Scale; PD = Parkinson disease; STN = subthalamic nucleus; UPDRS = Unified Parkinson's Disease Rating Scale. 
the STN in patients with postoperative cognitive decline, and within the ZI in patients with no decline (for the right side, figure 3B). In patients with cognitive decline vs without, the left stimulating contacts were located more posteriorly and deeper. A significant positive relationship was found between both the left and right anterior-Y coordinates of the stimulating contacts and the changes in the "frontal," verbal fluency (category and phonemic), and free-recall scores (figure 3D). Patients with PD who had a higher right $\mathrm{Y}$ coordinate $(>10.6 \mathrm{~mm})$ vs lower $(\leq 10.6$ $\mathrm{mm}$ ) had significant higher scores for verbal fluency, with a smaller decrease in the frontal and verbal fluency scores ( $p<0.01$, not shown). The left anterior$\mathrm{Y}$ coordinate was also positively correlated with the changes in the initiation and memory scores (MDRS, $p<0.01$, not shown) and patients with higher left $\mathrm{Y}$ coordinates showed significantly less decrease in the MDRS score after surgery ( $p<0.01$, not shown). The right and left depth $(Z)$ coordinates were also significantly related to the change in the memoryMDRS score (figure 3D), with a smaller decrease in patients with a lower right $\mathrm{Z}$ coordinate (not shown). No difference in the stimulation measures was found between groups (not shown).

Psychiatric outcome. Before surgery, 45 patients showed symptoms of depression. The mean MADRS score did not change significantly after surgery (table 1). Eightyfour patients showed no postoperative mood disorders, 26 of 45 depressive patients improved their mood status, and 27 developed depression (figure 1). No significant difference was found between patients who went on to develop or maintain depressive signs after surgery ( $\mathrm{n}=46)$ vs patients whose depression improved ( $\mathrm{n}=26$ ), except for lower pre- and postoperative cognitive scores in depressive patients $(p<0.006)$. No significant difference was found for the parameter settings or contact locations between groups.

Nineteen patients presented with transient hypomania in the perioperative period, relieved by modifying stimulation parameter settings and/or medication (figure 1). This group of patients had (1) younger age, (2) shorter disease duration, and (3) similar severity of parkinsonian motor disability (off treatment) with fewer residual motor signs with dopaminergic drug treatment (figure 4) and MADRS score (not shown). After surgery, these patients also showed lower ADL (on treatment) and MADRS scores. No significant difference was found for the parameter settings between groups, but the mean coordinates of contacts inducing hypomania were found to be significantly deeper with a more frequent position in the intermediate-AS-STN (53\% vs $31 \%)$ and the SN ( $8 \%$ vs $1.5 \%$ ), and less frequently in the ZI ( $3 \%$ vs
$13 \%)(p=0.009$, figure 4). See e-Results for further details of the results.

DISCUSSION In this large single-center cohort of highly selected patients with PD who underwent bilateral STN-DBS, we showed that (1) the most effective target for the alleviation of PD motor symptoms and levodopa-induced motor complications is the STN and not the surrounding structures, (2) the occurrence of postoperative cognitive decline is mainly related to the surgical procedure, with stimulation sites associated with memory decline being located more ventral, and (3) stimulationinduced hypomania is related to both the form of the disease and deeper contact locations, whereas postoperative depression was only found to be related to preexisting depressive signs and lower cognitive performance.

To determine whether or not bilateral STN stimulation performed under the "best" conditions with the best patient candidates might be deleterious, this study was conducted in a large homogeneous population of patients with PD selected using strict inclusion criteria. In consequence, the influence of preoperative features (age, levodopa responsiveness, and preoperative cognitive status) on the postoperative outcome could have been masked, at least in part. The role of the contact locations was examined by using a deformable atlas that provides a $1-\mathrm{mm}$ precision, ${ }^{25}$ and functional STN subdivisions were obtained from track tracings in monkeys. ${ }^{26}$ Recent neurophysiologic and imaging studies performed in healthy subjects and patients with PD suggest that a similar STN functional organization exists (posteriorSM, intermediate-AS, and anterior-limbic). ${ }^{11,27,28}$ This objective evaluation of stimulation sites has also been applied by other teams ${ }^{29}$ and in multicenter clinical research protocols. ${ }^{30}$ The electrode locations in our patients were most frequently located within the intermediate-AS part of the STN, with only a small number of bilateral locations in the posteriorSM-STN. This probably results from our presurgical planning that targeted the center of the $\mathrm{STN}^{19}$ with a trajectory that provides better intraoperative electrophysiologic recordings and acute clinical effects, especially alleviation of akinesia. ${ }^{31}$

For such a large population of patients, the effect of DBS-STN on parkinsonian motor symptoms can be considered dramatic as judged by the $64 \%$ improvement in motor disability with stimulation alone. Such improvement is greater than that reported by others using less restrictive inclusion criteria., ${ }^{6,7}$ This argues for the strict selection of patients to obtain the best motor outcome with minimum side effects.

The effects on parkinsonian disability showed no difference whether stimulation was performed within 

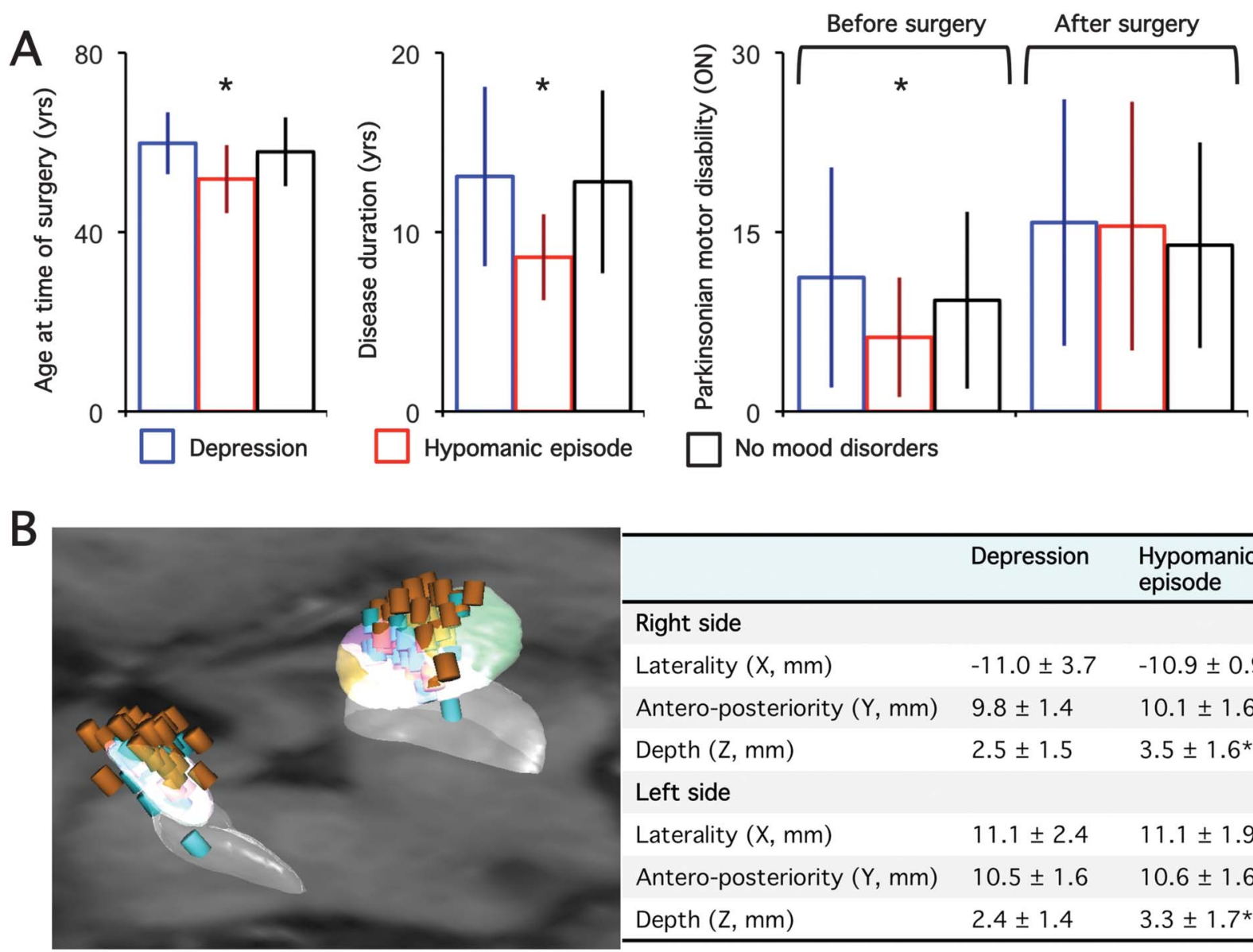

\begin{tabular}{lll}
\hline & Depression & $\begin{array}{l}\text { Hypomanic } \\
\text { episode }\end{array}$ \\
\hline Right side & & \\
Laterality (X, mm) & $-11.0 \pm 3.7$ & $-10.9 \pm 0.9$ \\
Antero-posteriority (Y, mm) & $9.8 \pm 1.4$ & $10.1 \pm 1.6$ \\
Depth (Z, mm) & $2.5 \pm 1.5$ & $3.5 \pm 1.6^{\star}$ \\
Left side & $11.1 \pm 2.4$ & $11.1 \pm 1.9$ \\
Laterality (X, mm) & $10.5 \pm 1.6$ & $10.6 \pm 1.6$ \\
Antero-posteriority (Y, mm) & $2.4 \pm 1.4$ & $3.3 \pm 1.7^{*}$ \\
\hline Depth (Z, mm) & & \\
\hline
\end{tabular}

(A) Differences in age at time of surgery, disease duration, parkinsonian motor disability "on" drug before surgery and "on" stimulation alone after surgery in patients with Parkinson disease (PD) who had postoperative depression (blue bars), hypomanic episodes (red bars), or no mood disorders (black bars). (B) Left panel: stimulating contacts used in patients with PD who had postoperative depression (blue cylinders) or hypomania (brown cylinders); right panel: mean (SD) $X, Y$, and $Z$ coordinates in the anterior commissure-posterior commissure space of the stimulating contacts in patients with PD who had postoperative depression or hypomania. Asterisks indicate significant differences between groups.

the posterior-SM or intermediate-AS parts of the STN, with the best motor improvements found with the most anterior electrode locations (closer to the associative part of the STN; figure 2, C and D). This suggests that stimulation of the intermediate-AS part of the STN represents a preferential location to improve parkinsonian motor akinesia. ${ }^{18}$ However, other authors have proposed a more dorsoposterior target within the STN, ${ }^{32}$ where the most powerful $\beta$ oscillatory activity is recorded and correlated with best motor improvement. ${ }^{33}$ This apparent discrepancy may be explained by the following facts: (1) the entire volume of the STN receives afferent projections from the motor cortex via the "hyperdirect pathway," whose activity is modulated by STN stimulation and related to the motor effects of this treatment ${ }^{34}$; (2) motor and associative territories of the STN are separated by functional gradients, ${ }^{26}$ suggesting that neurons in the central part of the STN may have connections with both SM and AS inputs; and (3) the somatotopic organization of the STN neurons in patients with PD is partly lost. ${ }^{35}$ However, akinesia comprises motor but also cognitive and motivational components, understandably improved by targeting the associative neuronal network. Stimulation of the ZI area gave poorer motor improvement (49\%) with no evidence of a specific effect on tremor severity, as previously reported. ${ }^{8}$

Chronic stimulation of the associative STN induced no decline in executive functions, in contrast to acute stimulation ${ }^{27}$ or in patients with low cognitive capacity, ${ }^{4}$ and more anterior stimulation (close to the associative STN) was related to an increase in executive function 1 year after surgery. This is in line with anterior positioning of electrodes reported in patients with PD showing no decline in mental status scores after surgery. ${ }^{14}$ Ventral electrode location was found to be associated with memory decline, as previously observed. ${ }^{36}$ However, the fact that patients with $\mathrm{PD}$ who had a 1-year postoperative decline 
showed no further cognitive decline 2 years after surgery (figure 2C) suggests that the main factor related to its occurrence is the surgical procedure creating a microlesion. ${ }^{15}$ Facts supporting this hypothesis are that (1) an acute decline in some executive functions is observed in the days after surgery ${ }^{37}$ or in the absence of STN stimulation, ${ }^{38}$ and (2) similar cognitive side effects exist, whatever the surgical target, i.e., the STN or the globus pallidus interna. ${ }^{6,7,38}$

Stimulation of the more ventral (limbic) part of the STN induced hypomania, as previously reported in both patients with $\mathrm{PD}^{11,12}$ and patients with psychiatric disorders. ${ }^{30}$ Hypomania was mainly observed in younger patients, those with shorter disease duration, and those with a higher levodopa responsiveness, i.e., a disease profile similar to that observed in patients with dopaminergic dysregulation. ${ }^{39}$ Conversely, postoperative depression was not found to be related to electrode location, but to the presence of a preoperative depression, parkinsonian mental deficit, and axial motor signs, as previously reported. ${ }^{40}$

The STN, therefore, and not the surrounding areas, appears to be the ideal target to improve motor disability in patients with PD. This technique may provoke memory or emotional disturbances, especially if the electrodes are too ventral in the STN. This confirms the role of the STN in motor and nonmotor processing and its possible importance in nonmotor diseases.

\section{AUTHOR CONTRIBUTIONS}

M.-L.W., M.S., V.C., E.B., J.Y., and Y.A. were responsible for the concept and design of the study. J.Y., M.-L.W., L.M., J.Y., and Y.A. obtained funding for the study. C.K., S.N., P.C., and H.B. performed the surgical procedure and B.P. and M.-L.W. performed the intraoperative electrophysiologic targeting. M.-L.W., A.W., V.C., V.M., F.P., L.M., Y.W., P.Z., A.H., M.V., Y.W., A.-M.B., D. Grabli, and J.-L.H performed clinical investigations and acquired clinical and neuropsychological data. D.D. and D. Galanaud acquired the radiologic data. M.S., E.B., and J.Y. performed electrode location analysis. H.B. and S.F.-V. performed voxel-based morphometric analysis. The data were analyzed by M.-L.W. and J.-L.G. M.-L.W. drafted the report and M.S., V.C., C.K., L.M., B.P., V.M., J.Y., and Y.A. provided substantial input to the first draft. M.-L.W. and E.B. created the figures. All authors reviewed the manuscript. The study was supervised by M.-L.W. and Y.A.

\section{ACKNOWLEDGMENT}

The authors extend their deepest thanks to all patients who participated in this study.

\section{STUDY FUNDING}

Supported by the French Ministry of Health, Medtronic, and the Agence Nationale de la Recherche Programme for Young Researchers (R05121DS) and ANR-06-NEURO-006-01

\section{DISCLOSURE}

M. Welter received research support from the Institut du Cerveau de la Moelle épinière Foundation and the Agence Nationale de la Recherche and consulting fees from Medtronic and Teva-Lundbeck. M. Schüpbach received research support and consulting fees from Medtronic and served as an expert witness for Lundbeck. V. Czernecki, C. Karachi, S. Fernandez-Vidal, J. Golmard, G. Serra, S. Navarro, A. Welaratne,
A. Hartmann, V. Mesnage, and F. Pineau report no disclosures relevant to the manuscript. P. Cornu received consulting fees and payment for development of educational presentations from Medtronic. B. Pidoux reports no disclosures relevant to the manuscript. Y. Worbe received a research grant from the Fyssen Foundation. P. Zikos reports no disclosures relevant to the manuscript. D. Grabli received lectures fees and travel grants from Lundbeck, Teva, Novartis, UCB, BoehringerIngelheim, and AbbVie. He has consulting activity for AbbVie, and research grants from the Direction Générale de l'Organisation des Soins, Institut National de la Santé et de la Recherche Médicale (INSERM), Michael J. Fox Foundation for Parkinson Research, France Parkinson Association, and French Patient Association for Essential Tremor. D. Galanaud received consulting fees from Actelion, Sanofi-Aventis, and Biogen Idec and travel grants from Olea Medical. A. Bonnet, H. Belaid, and D. Dormont report no disclosures relevant to the manuscript. M. Vidailhet received research grants from Metz, UCB, Novartis, INSERM (Cossec) and ANR, patients associations France Parkinson, AMADYS, and travel grants from the Movement Disorders Society and Dystonia Coalition. L. Mallet received travel grants from Medtronic and consulting fees from AstraZeneca J. Houeto received consulting fees and payment for development of educational presentations from Medtronic. E. Bardinet received a research grant from Medtronic. J. Yelnik and Y. Agid report no disclosures relevant to the manuscript. Go to Neurology.org for full disclosures.

Received August 27, 2013. Accepted in final form December 10, 2013.

\section{REFERENCES}

1. Limousin P, Krack P, Pollak P, et al. Electrical stimulation of the subthalamic nucleus in advanced Parkinson's disease. N Engl J Med 1998;339:1105-1111.

2. Parsons TD, Rogers SA, Braaten AJ, Woods SP, Troster AI. Cognitive sequelae of subthalamic nucleus deep brain stimulation in Parkinson's disease: a meta-analysis. Lancet Neurol 2006;5:578-588.

3. Voon V, Kubu C, Krack P, Houeto JL, Troster AI. Deep brain stimulation: neuropsychological and neuropsychiatric issues. Mov Disord 2006;21(suppl 14):S305-S327.

4. Williams A, Gill S, Varma T, et al. Deep brain stimulation plus best medical therapy versus best medical therapy alone for advanced Parkinson's disease (PD SURG trial): a randomised, open-label trial. Lancet Neurol 2010;9:581-591.

5. Daniels C, Krack P, Volkmann J, et al. Is improvement in the quality of life after subthalamic nucleus stimulation in Parkinson's disease predictable? Mov Disord 2011;26: 2516-2521.

6. Follett KA, Weaver FM, Stern M, et al. Pallidal versus subthalamic deep-brain stimulation for Parkinson's disease. N Engl J Med 2010;362:2077-2091

7. Odekerken VJ, van Laar T, Staal MJ, et al. Subthalamic nucleus versus globus pallidus bilateral deep brain stimulation for advanced Parkinson's disease (NSTAPS Study): a randomised controlled trial. Lancet Neurol 2013;12: 37-44.

8. Plaha P, Ben-Shlomo Y, Patel NK, Gill SS. Stimulation of the caudal zona incerta is superior to stimulation of the subthalamic nucleus in improving contralateral parkinsonism. Brain 2006;129:1732-1747.

9. Welter ML, Houeto JL, Tezenas du Montcel S, et al. Clinical predictive factors of subthalamic stimulation in Parkinson's disease. Brain 2002;125:575-583.

10. Bonneville F, Welter ML, Elie C, et al. Parkinson disease, brain volumes, and subthalamic nucleus stimulation. Neurology 2005;64:1598-1604.

11. Mallet L, Schupbach M, N'Diaye K, et al. Stimulation of subterritories of the subthalamic nucleus reveals its role in the integration of the emotional and motor aspects of 
behavior. Proc Natl Acad Sci USA 2007;104:1066110666.

12. Ulla M, Thobois S, Llorca PM, et al. Contact dependent reproducible hypomania induced by deep brain stimulation in Parkinson's disease: clinical, anatomical and functional imaging study. J Neurol Neurosurg Psychiatry 2011;82:607-614.

13. Derost PP, Ouchchane L, Morand D, et al. Is DBS-STN appropriate to treat severe Parkinson disease in an elderly population? Neurology 2007;68:1345-1355.

14. York MK, Wilde EA, Simpson R, Jankovic J. Relationship between neuropsychological outcome and DBS surgical trajectory and electrode location. J Neurol Sci 2009;287: 159-171.

15. Mann JM, Foote KD, Garvan CW, et al. Brain penetration effects of microelectrodes and DBS leads in STN or GPi. J Neurol Neurosurg Psychiatry 2009;80:794-797.

16. Saint-Cyr JA, Hoque T, Pereira LC, et al. Localization of clinically effective stimulating electrodes in the human subthalamic nucleus on magnetic resonance imaging. J Neurosurg 2002;97:1152-1166.

17. McClelland S III, Ford B, Senatus PB, et al. Subthalamic stimulation for Parkinson disease: determination of electrode location necessary for clinical efficacy. Neurosurg Focus 2005;19:E12.

18. Hilliard JD, Frysinger RC, Elias WJ. Effective subthalamic nucleus deep brain stimulation sites may differ for tremor, bradykinesia and gait disturbances in Parkinson's disease. Stereotact Funct Neurosurg 2011;89:357-364.

19. Bejjani BP, Dormont D, Pidoux B, et al. Bilateral subthalamic stimulation for Parkinson's disease by using threedimensional stereotactic magnetic resonance imaging and electrophysiological guidance. J Neurosurg 2000;92: 615-625.

20. Pillon B. Neuropsychological assessment for management of patients with deep brain stimulation. Mov Disord 2002; 17(suppl 3):S116-S122.

21. Schmidt R, Freidl W, Fazekas F, et al. The Mattis Dementia Rating Scale: normative data from 1,001 healthy volunteers. Neurology 1994;44:964-966.

22. Montgomery SA, Asberg M. A new depression scale designed to be sensitive to change. Br J Psychiatry 1979;134: 382-389.

23. Sheehan DV, Lecrubier Y, Sheehan KH, et al. The MiniInternational Neuropsychiatric Interview (M.I.N.I.): the development and validation of a structured diagnostic psychiatric interview for DSM-IV and ICD-10. J Clin Psychiatry 1998;59(suppl 20):22-33.

24. Yelnik J, Bardinet E, Dormont D, et al. A threedimensional, histological and deformable atlas of the human basal ganglia: I: atlas construction based on immunohistochemical and MRI data. Neuroimage 2007;34: 618-638.

25. Bardinet E, Bhattacharjee M, Dormont D, et al. A threedimensional histological atlas of the human basal ganglia: II: atlas deformation strategy and evaluation in deep brain stimulation for Parkinson disease. J Neurosurg 2009;110: 208-219.

26. Haynes WI, Haber SN. The organization of prefrontalsubthalamic inputs in primates provides an anatomical substrate for both functional specificity and integration: implications for basal ganglia models and deep brain stimulation. J Neurosci 2013;33:4804-4814.

27. Frankemolle AM, Wu J, Noecker AM, et al. Reversing cognitive-motor impairments in Parkinson's disease patients using a computational modelling approach to deep brain stimulation programming. Brain 2010;133: 746-761.

28. Lambert C, Zrinzo L, Nagy Z, et al. Confirmation of functional zones within the human subthalamic nucleus: patterns of connectivity and sub-parcellation using diffusion weighted imaging. Neuroimage 2012;60:83-94.

29. Ferraye MU, Debu B, Fraix V, et al. Effects of pedunculopontine nucleus area stimulation on gait disorders in Parkinson's disease. Brain 2010;133:205-214.

30. Mallet L, Polosan M, Jaafari N, et al. Subthalamic nucleus stimulation in severe obsessive-compulsive disorder. N Engl J Med 2008;359:2121-2134.

31. Houeto JL, Welter ML, Bejjani PB, et al. Subthalamic stimulation in Parkinson disease: intraoperative predictive factors. Arch Neurol 2003;60:690-694.

32. Hamel W, Fietzek U, Morsnowski A, et al. Deep brain stimulation of the subthalamic nucleus in Parkinson's disease: evaluation of active electrode contacts. J Neurol Neurosurg Psychiatry 2003;74:1036-1046.

33. Zaidel A, Spivak A, Grieb B, Bergman H, Israel Z. Subthalamic span of beta oscillations predicts deep brain stimulation efficacy for patients with Parkinson's disease. Brain 2010;133:2007-2021.

34. Li Q, Ke Y, Chan DC, et al. Therapeutic deep brain stimulation in parkinsonian rats directly influences motor cortex. Neuron 2012;76:1030-1041.

35. Rodriguez-Oroz MC, Rodriguez M, Guridi J, et al. The subthalamic nucleus in Parkinson's disease: somatotopic organization and physiological characteristics. Brain 2001;124:1777-1790.

36. Tsai ST, Lin SH, Lin SZ, Chen JY, Lee CW, Chen SY. Neuropsychological effects after chronic subthalamic stimulation and the topography of the nucleus in Parkinson's disease. Neurosurgery 2007;61:E1024-E1029.

37. Lefaucheur R, Derrey S, Martinaud O, et al. Early verbal fluency decline after STN implantation: is it a cognitive microlesion effect? J Neurol Sci 2012;321:96-99.

38. Okun MS, Fernandez HH, Wu SS, et al. Cognition and mood in Parkinson's disease in subthalamic nucleus versus globus pallidus interna deep brain stimulation: the COMPARE trial. Ann Neurol 2009;65:586-595.

39. Weintraub D, Koester J, Potenza MN, et al. Impulse control disorders in Parkinson disease: a cross-sectional study of 3090 patients. Arch Neurol 2010;67:589-595.

40. Cummings JL. Depression and Parkinson's disease: a review. Am J Psychiatry 1992;149:443-454. 


\section{Neurology}

\section{Optimal target localization for subthalamic stimulation in patients with Parkinson disease}

Marie-Laure Welter, Michael Schüpbach, Virginie Czernecki, et al.

Neurology 2014;82;1352-1361 Published Online before print March 19, 2014

DOI 10.1212/WNL.0000000000000315

This information is current as of March 19, 2014

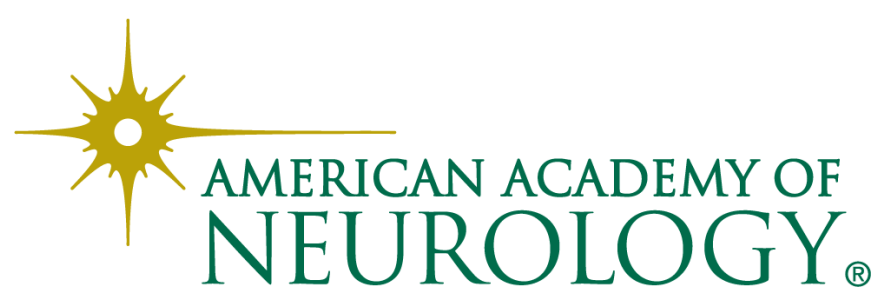




\section{Updated Information \& Services}

\section{Supplementary Material}

References

Citations

Subspecialty Collections

Permissions \& Licensing

\section{Reprints}

including high resolution figures, can be found at: http://n.neurology.org/content/82/15/1352.full

Supplementary material can be found at: http://n.neurology.org/content/suppl/2014/03/19/WNL.0000000000000 315.DC1

This article cites 40 articles, 9 of which you can access for free at: http://n.neurology.org/content/82/15/1352.full\#ref-list-1

This article has been cited by 1 HighWire-hosted articles: http://n.neurology.org/content/82/15/1352.full\#\#otherarticles

This article, along with others on similar topics, appears in the following collection(s):

\section{Class III}

http://n.neurology.org/cgi/collection/class_iii

MRI

http://n.neurology.org/cgi/collection/mri

Neuropsychological assessment

http://n.neurology.org/cgi/collection/neuropsychological_assessment Parkinson's disease/Parkinsonism

http://n.neurology.org/cgi/collection/parkinsons_disease_parkinsonism Surgery/Stimulation

http://n.neurology.org/cgi/collection/surgery-stimulation

Information about reproducing this article in parts (figures,tables) or in its entirety can be found online at:

http://www.neurology.org/about/about_the_journal\#permissions

Information about ordering reprints can be found online:

http://n.neurology.org/subscribers/advertise

Neurology ${ }^{\circledR}$ is the official journal of the American Academy of Neurology. Published continuously since 1951, it is now a weekly with 48 issues per year. Copyright @ 2014 American Academy of Neurology. All rights reserved. Print ISSN: 0028-3878. Online ISSN: 1526-632X.

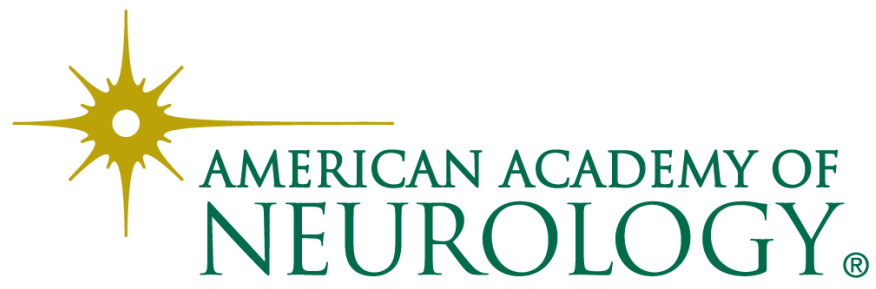

